\title{
THE POTENTIAL LIFE SPAN AND ULTIMATE SURVIVAL OF FRESH RED BLOOD CELLS IN NORMAL HEALTHY RE- CIPIENTS AS STUDIED BY SIMULTANEOUS $\mathrm{CR}^{51}$ TAGGING AND DIFFERENTIAL HEMOLYSIS ${ }^{1}$
}

\author{
By G. S. EADIE ANd IVAN W. BROWN, JR. With the technical assistance of \\ W. GRANDY CURTIS \\ (From the Departments of Physiology and Pharmacology and of Surgery, Duke University \\ School of Medicine, Durham, N. C.)
}

(Submitted for publication September 20, 1954 ; accepted December 15, 1954)

Death of the red blood cell is thought to occur either by senescence when it reaches the end of its life span or by a process of random destruction unrelated to the age of the cell $(1,2)$. In a normally distributed mixed population of red cells senescence would result in the daily loss of approximately the same number of erythrocytes while random destruction would remove each day a constant proportion of the remaining cells. These two processes are therefore clearly distinguishable by survival experiments. Although this theory implies that the life span, as distinct from the actual survival time, is a characteristic of the cell itself and independent of the environment so that it is unaffected even by transfusion, no direct experimental evidence exists as to whether or not this is, in fact, the case. To obtain such evidence it is necessary to use cells that can be identified either by the blood group to which they belong as in the Ashby method, or by the incorporation of an isotope such as $\mathrm{N}^{15}, \mathrm{Fe}^{55}, \mathrm{Fe}^{58}$, or $\mathrm{Cr}^{51}$. Identification with radiochromium is perhaps the simplest because of the ease of incorporation and of measurement, its greatest defect being that its union with the red cell is not quite irreversible, approximately 1 per cent of the remaining isotope being lost, presumably by elution, daily (3). This makes direct calculation of the life span and rate of random loss impossible by the usual regression methods, and although a method exists by which an approximation can sometimes be arrived at, it is not certain whether this would give satisfactory answers in this case. Moreover very little is known about the accuracy and reproducibility

1 This investigation was supported in part by a research grant H-1226(C3) from the National Heart Institute, of the National Institutes of Health, Public Health Service. of determinations of life span made by any method, and it was hoped that information might be gained on this point also.

\section{METHODS}

Two experiments were performed. In each a large volume of blood, a liter or more, was drawn from a healthy male donor belonging to group $\mathrm{O}$, divided into three parts, and transfused into three healthy, compatible, male recipients belonging to group $A$, sterile precautions being used throughout. The fate of the transfused blood was followed by two different methods: by tagging the cells with radiochromium, and by a modification of the Ashby method described below using differential hemolysis instead of agglutination.

Donor blood was drawn into plastic bags containing $75 \mathrm{ml}$. of Anticoagulant Acid Citrate Dextrose Solution (Solution A), U. S. P. After thorough mixing about $50 \mathrm{ml}$. were removed and incubated at room temperature for 45 mins. with a sterile solution of sodium chromate containing 50 to 100 microcuries of $\mathrm{Cr}^{\mathrm{s}}$. The specific activity was 862 millicuries per $\mathrm{gm}$. of chromium in the first experiment and 1,358 millicuries per $\mathrm{gm}$. in the second. The cells were then centrifuged, washed three times with ice-cold saline, and finally suspended in saline. The hematocrit values of this mixture were determined by a procedure previously used in this laboratory which consists of centrifuging the blood at 3,000 rpm. for 45 mins. and correcting the resulting figure for the 3 per cent of the saline that had been shown to be trapped among the corpuscles under our conditions (4). The radioactivity of the red cell suspension was measured in a well type scintillation counter ${ }^{2}$ after diluting 1:100 with distilled water. Meanwhile, immediately before transfusion, about $300 \mathrm{ml}$. of blood was removed from each recipient by venipuncture so that the subsequent blood infusion would not produce any great change in the total red cell mass. Accurately measured samples of approximately $10 \mathrm{ml}$. of the well mixed blood treated with $\mathrm{Cr}^{\text {sil }}$ were then injected by calibrated syringes into each recipient and samples taken 10 and 20 mins. after injection. From the radioactivity and hematocrit value of these samples, the total circulating red cell mass was

2 Obtained from N. Wood Counter Laboratories, 5491 Blackstone Avenue, Chicago, Illinois. 
TABLE I

\begin{tabular}{|c|c|c|c|c|}
\hline Donor & Recipient & $\begin{array}{l}\text { Vol. of injected } \\
\text { chromated red cells } \\
\text { ml. }\end{array}$ & $\begin{array}{l}\text { RBC volume } \\
\text { of reciplent } \\
\text { Uters }\end{array}$ & $\begin{array}{c}\text { Vol. of injected non- } \\
\text { chromated red celle } \\
\text { ml. }\end{array}$ \\
\hline$I$ & 1 & 3.71 & $\begin{array}{l}1.949 \\
1.887\end{array}$ & 145.2 \\
\hline I & 2 & 3.68 & $\begin{array}{l}1.865 \\
2.104^{\mathrm{av} .} 1.984\end{array}$ & 98.6 \\
\hline I & 3 & 3.59 & $\begin{array}{l}1.916 \\
\text { av. } 1.954\end{array}$ & 123.5 \\
\hline II & 4 & 3.98 & $\begin{array}{l}1.837 \\
1.887\end{array}$ & 164.7 \\
\hline II & 5 & 3.93 & $\begin{array}{l}1.324 \\
\text { av. } 1.324\end{array}$ & 153.9 \\
\hline II & 6 & 4.00 & $\begin{array}{l}1.814 \\
1.808^{\mathrm{av}} \cdot 1.811\end{array}$ & 165.0 \\
\hline
\end{tabular}

calculated (Table I). Following this each recipient received $250 \mathrm{ml}$. to $350 \mathrm{ml}$. of chromium-free blood of which the exact volume had been determined by weighing and measuring the specific gravity. In addition, the hematocrit value, and, in the case of the second donor, the red cell count of the transfused blood, were also determined. It should be noted that the volume of chromate-free blood was very much greater than that of the chromium-tagged blood; most of the cells followed by differential hemolysis had not been exposed to chromium, and any possible effect of radiochromium on survival would be largely avoided.

Some thirty samples for analysis were obtained from each recipient over a period of about 100 days spaced as follows. Two samples were taken the first day, one 30 mins. and the other two hours after transfusion. Following this samples were taken daily for a week, and thereafter twice a week. In each case blood was collected in tubes containing $0.2 \mathrm{mg}$. of dried heparin. Radioactivity was determined on each sample, diluted if necessary with distilled water, and was corrected for the decay of radioactivity of the chromium itself. ${ }^{8}$ The activity in counts per minute was then divided by the hematocrit reading and expressed as cpm per $\mathrm{ml}$. of red cells. Multiplication by the previously determined red cell mass gave the total circulating radioactivity assuming no change in red cell mass. In this form it was possible to correct for loss of chromium in the samples by using a formula previously given (4).

3 In order to have a check on the scintillation counter readings the activity of a sample of the radiochromium was measured at the same time as the blood samples. From these readings the half-life was calculated to be 27.4 and 27.3 days. This is to be compared with the value of $27.75 \pm 0.3$ days given by Lyon (6). Measurements were therefore reasonably accurate.
The number of circulating donor cells was counted by a method of differential hemolysis as follows.* Human anti-A hemolytic serum was obtained from a group B volunteer who had been injected with $5 \mathrm{ml}$. of Blood Group Specific Substances A and B Solution (Sharp and Dohme) once weekly for three weeks. To this, fresh complement was added in the form of guinea-pig serum. For this purpose guinea-pigs were chosen which had a natural anti-A hemolysin in their sera (5); other animals were found to be entirely unsatisfactory. The guinea-pig anti-A serum titer was enhanced by intraperitoneal injections of a mixture of 10 parts of sterile meconium from a newborn group A secretor infant, one part of Arlecel $A^{5}$ and nine parts of Bayol $F^{6}(8)$. The human and guinea-pig sera were mixed in equal volumes, other proportions being found to be less effective. They were, of course, tested to ensure absence of species specific hemolysins and hemolysins for group $O$ cells.

Blood to be counted was diluted with saline in the ratios $1: 25,1: 50$ or $1: 100$ (or $1: 26,1: 51$ or $1: 101$ ) depending on the number of donor cells anticipated; this was done in order that approximately the same number of cells might be counted throughout the experiment without unduly increasing the number of spreads. This

4 Since the completion of this work a method of differential hemolysis has been published by Hurley and Weisman (7). Their method differs from ours chiefly in the use of the recipient's serum rather than guinea-pig serum as a source of complement. By using the guinea-pig serum it was possible to make counts at lower blood dilutions with greater reproducibility.

- Obtained from Atlas Powder Company, Wilmington, Delaware.

- Obstained from Esso Standard Oil Company, Bayonne, New Jersey. 
helps to minimize the decrease in accuracy of counting which would otherwise occur towards the end of the experiment with the decrease in the numbers of donor cells. The diluted cell suspension was mixed with an equal volume of the hemolytic antiserum mixture, a proportion found experimentally to be the most satisfactory, and incubated in a water bath at $37^{\circ} \mathrm{C}$. for 30 mins. with occasional shaking. Counts were made by a photographic method (9). While this hemolytic method is not completely free from various errors, nevertheless it is our experience that results obtained with it are much more accurate than with the usual differential agglutination procedures (10). Counts expressed as millions of cells per $\mathrm{cu}$. $\mathrm{mm}$. were divided by the hematocrit reading expressed as a decimal rather than a per cent and multiplied by 100 to avoid small numbers. For example a count of 0.450 million cells per cu. $\mathrm{mm}$. and a hematocrit reading of 0.45 ( 45 per cent) would give a nonhemolyzed cell index of 100 . This gives the count in terms of the red cell mass rather than the blood volume and thus avoids errors due to fluctuations in the latter.

\section{RESULTS AND DISCUSSION}

Difficulties in interpretation of curves obtained with radiochromium stem primarily from the fact that some chromium leaves the red cell before its destruction probably by elution (3); this is thought to occur at a rate proportional to the average concentration of chromium remaining in the erythrocytes at that moment, and independent of the age of the cell, i.e., at a rate equal to $k_{1} p$ where $p$ is the corrected radioactivity on a given day. In addition to this, radiochromium is lost when cells disappear for any reason, whether by senescence or random destruction. Since the latter occurs at a rate equal to $k_{2} p$, its rate may be added to that of elution to give $\left(k_{1}+k_{2}\right) p$, and we may substitute $k$ for $k_{1}+k_{2}$. The constant $k_{2}$ of course in man is frequently zero, i.e., there is no random destruction, and in this case $\mathbf{k}$ will equal $\mathbf{k}_{\mathbf{1}}{ }^{7}$ Because the rates of random loss may be added in this way it is possible to describe the disappearance of radiochromium from circulating blood by the equation $(2,11)$

$$
N=N_{0}(1-t / T) e^{-k t}, t \leqq T
$$

where $\mathrm{N}$ is the radioactivity count, corrected as described under Methods, on day $t, N_{0}$ the cor-

\footnotetext{
7 Decay of radioactivity follows the same law as random loss, and the radioactivity decay constant, $\lambda$, may also be added and $k^{\prime}=\left(k_{1}+k_{2}+\lambda\right)$ may be substituted for $k$ in the equation above instead of correcting the counts for decay as described above.
}

responding count on day zero, and $T$ the potential life span. In dealing with radioactive decay it is customary to give the half-life rather than the coefficient of decay, $\lambda$. These are, however, readily convertible since $0.5=\mathrm{e}^{-\lambda t}$ leads to $\lambda=-0.693 / \mathrm{t}$, $t$ in this instance being the half-life. The situation is different with red cell disappearance where there are two parameters, $T$ and $k$, instead of one. There is consequently an infinite number of pairs of values of $\mathrm{T}$ and $\mathrm{k}$ for each value of the half-life which is therefore ambiguous. Finally, it should be noted that this equation assumes that chromium set free by elution or by destruction of the red cell with which it is combined, is not used for labeling other red cells. This is in agreement with the findings of Ebaugh, Emerson, and Ross (12).

Fitting data to equation (1) is difficult because it is impossible to reduce it to a straight line by using logarithms or other devices; and although data for the first two or three weeks plotted in this way do not depart greatly from linearity, the error is sufficient to make estimates of $T$ and $k$ unreliable and that of $\mathrm{N}_{0}$ somewhat too high. Assumption of a value for $T$ permits evaluation of $k$ (13), but this is biased by the assumption with regard to $T$. An approximation to a least squares solution may, however, be made by a method given by Deming (14). Values are assumed for the three parameters of equation (1) $\mathrm{N}_{0}, \mathrm{~T}$ and $\mathrm{k}$; these are inserted into the expression

$$
\mathrm{N}-\mathrm{N}_{\mathrm{o}}(1-\mathrm{t} / \mathrm{T}) \mathrm{e}^{-k t}
$$

and into the expressions obtained by its partial differentiation with respect to each of the three constants; this is done for each value of $t$ for which experimental data exist. Four columns of figures are thus obtained; from the sums of their squares and cross-products three normal equations are formed whose solution (preferably by the methods of matrix algebra) furnishes three numbers which, subtracted from the assumed values of the constants, give the first approximations to an unbiased estimate. Repetition of this procedure would yield a closer approximation, but this did not seem necessary in the case of any of the experiments reported here. Standard errors are calculated by determining the inverse matrix. The weighting procedure suggested by Deming seemed to be unnecessary since counts were made in such a way 

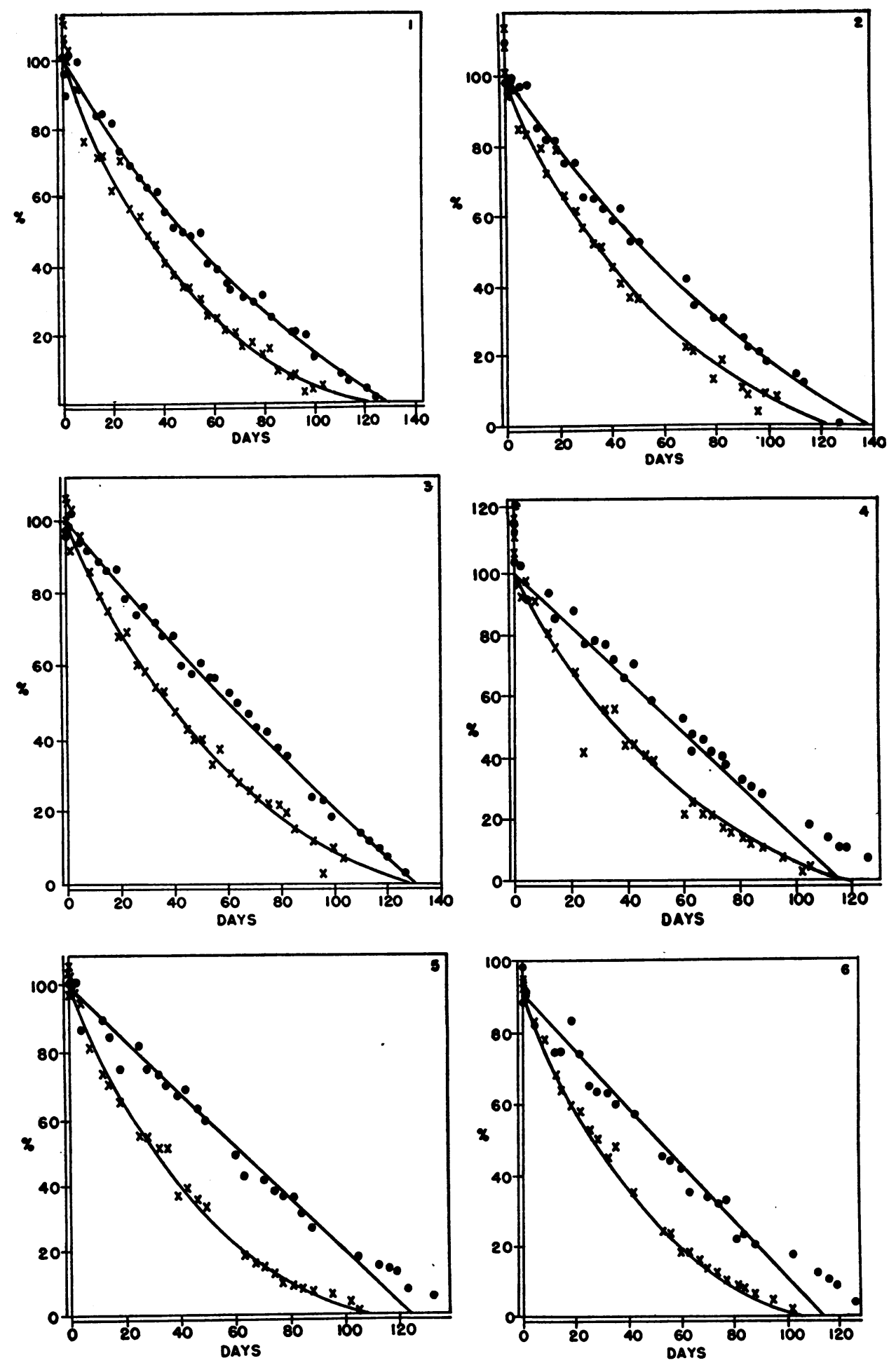

Fig. 1. Survival of Erythrocytes Transfused from Healthy Donors into Healthy Recipients Followed Simultaneously by Differential Hemolysis and Tagging with RADIOCHROMIUM

The index of non-hemolyzed cells $(\bullet)$ and corrected radioactivity $(X)$ are plotted on a scale where 100 per cent represents the value of No given in Table II, i.e., 100 per cent of the 
that the total number of radioactive counts or of red cells enumerated were approximately the same throughout the experiment, and accordingly it was not used. Counts made on the day of transfusion were not used in order to avoid effects from the rapid elimination of any damaged cells (2).

From the values of $N_{0}, T$ and $k$ obtained by this analysis a disappearance curve was constructed for each recipient. These together with the data from which they were derived, are plotted in Figure 1. It is obvious that except for the initial and final periods the fit is very good and the experimental points lie randomly on either side of the line. There is thus no reason to think that the equation fails to represent adequately the rate of cell disappearance over the major part of its course, nor is there any evidence of relabeling by released chromium for the metal does not persist in the blood after transfused cells have been shown to disappear by the method of differential hemolysis. Departures are visible towards the end of the curves in the second experiment (Figure 1, curves 4,5 , and 6 ). This is particularly noticeable in the hemolysis data (solid circles). This is usually ascribed to the fact that life spans of individual cells are not all precisely equal but distributed around a mean $(1,2)$. Why this should not also be apparent in the first experiment (Figure 1 , curves 1,2 , and 3 ) is not clear, but there is no doubt of the absence of tailing throughout this group of curves. Because large experimental errors are commonly found in this part of the curve, it has not always been possible in the past to be certain of the presence or absence of such tailing, but with the increasing accuracy of methods now available it can be studied more carefully. If it should be found that a tail is only occasionally present, some revision of the present theory will probably be necessary.

Values for $\mathrm{N}_{0}, \mathrm{~T}$ and $\mathrm{k}$ obtained by the analysis are summarized in Table II. It will be seen that there is a considerable degree of variation in estimated life spans even for samples of blood from the same donor, and that differences also occur be- tween estimations made by different methods from the same recipient. Whether these differences are significant cannot be ascertained by the usual tests because of the wide range of variation in the standard errors. Bartlett's test (15) shows that the variance is not homogeneous in either experiment when cells were tagged with chromium, and was very questionably so with the hemolytic method in the first experiment. Comparisons were therefore made by a method based on Fisher's theory of fiducial probability (16), and also by the approximation suggested by Cochran and Cox (17). Neither of these tests showed a significant difference in values for potential life span attributable to the method or to the recipient. It may be noted, however, that values obtained by the radioisotope method tend to be lower than those obtained by hemolysis; the difference, while it does not reach the level of significance with the few data available, nevertheless tends to approach it, and might very well prove to be significant in a longer series. But, even if this were the case, the reason for it might quite as likely be a systematic experimental error in one of the methods as a change in life span. However this may be, it is quite clear that chromium has no significant deleterious effect at least on the life span.

Because of this absence of significant differences among various determinations on blood from the same donor, it was possible to pool data. For the first experiment the average life spans proved to be 128.7 days with a standard deviation of 4.6 ; for the second experiment the figures were 114.0 土7.7. The two variances are homogeneous, and the two values for the life span differed to a highly significant degree. The potential life span therefore differs depending on the donor and is independent of the environment.

The lack of uniformity in variance, already mentioned, appears, in the first experiment, to be related to the coefficient of random loss, but this is not the case in the second. It would seem reasonable to think that determinations made from data collected over a shorter period would show a The smooth curves were drawn from the equation in the text using the values for the constants in Table II. Each pair of curves was obtained from the same recipient (the number in the right upper corner is the recipient's number). Blood from the same donor was used in curves 1,2 , and 3 and another in curves 4,5 , and 6. 


\begin{tabular}{|c|c|c|c|c|c|c|}
\hline Expt. & $\begin{array}{l}\text { Reci- } \\
\text { plent }\end{array}$ & Method & df & $\mathbf{T}$ & $\mathbf{k}$ & $N_{0}$ \\
\hline \multirow{2}{*}{1} & \multirow{2}{*}{1} & a NHC & 29 & $129.29 \pm 3.61$ & $.00461 \pm .00073$ & $100.30 \pm 1.36$ \\
\hline & & b $C_{r}$ & 28 & $125.08 \pm 11.85$ & $.0125 \pm .0041$ & $3.35 \pm .06$ \\
\hline \multirow{10}{*}{2} & \multirow{2}{*}{2} & NHC & 23 & $137.01 \pm 3.57$ & $.00404 \pm .00071$ & $81.65 \pm 1.09$ \\
\hline & & b $C_{x}$ & 22 & $124.43 \pm 10.92$ & $.00978 \pm .00161$ & $3.39 \pm .073$ \\
\hline & \multirow{2}{*}{3} & NHC & 29 & $129.25 \pm 2.06$ & $.00069 \pm .00046$ & $86.06 \pm .91$ \\
\hline & & b $\mathbf{C r}$ & 27 & $127.07 \pm 5.15$ & $.00915 \pm .00281$ & $3.46 \pm 0.27$ \\
\hline & \multirow{2}{*}{4} & a NHC & 19 & $116.79 \pm 7.01$ & $.00100 \pm .00128$ & $81.77 \pm 1.61$ \\
\hline & & b $C_{x}$ & 24 & $118.33 \pm 13.40$ & $.00994 \pm .00204$ & $5.343 \pm .014$ \\
\hline & \multirow{2}{*}{5} & a NHC & 19 & $123.86 \pm 7.77$ & $.00056 \pm .00133$ & $120.72 \pm 2.14$ \\
\hline & & b $C_{x}$ & 23 & $108.70 \pm 8.23$ & $.01199 \pm .00146$ & $5.908 \pm .088$ \\
\hline & \multirow{2}{*}{6} & a NHC & 18 & $114.22 \pm 6.74$ & $.00044 \pm .01724$ & $99.86 \pm 2.63$ \\
\hline & & b $C_{r}$ & 21 & $102.10 \pm 5.84$ & $.00992 \pm .00105$ & $5.954 \pm .078$ \\
\hline
\end{tabular}

\begin{abstract}
*df : degrees of freedom, in this case equal to the total number of observations less 3 .

T: The average potential life span with its standard error. The latter indicates the precision of the determination, not the spread of life spans around the mean.

k: the fraction of cells disappearing daily by random destruction and the standard error of its determination.

$\mathrm{N}_{\mathrm{o}}$ : value for day zero by extrapolation, with the standard error of its determination. The difference between this and the expected value would indicate the number of irreversibly damaged cells in the transfusate.
\end{abstract}

greater variance than those collected over a longer one, but the data do not confirm this, again particularly in the second experiment.

Random loss, in the case of chromium experiments, includes both elution and random destruction, and $\mathrm{k}$ is therefore greater than in the hemolytic experiments where elution is absent. It was somewhat surprising to find that $k$ was not always zero in the latter experiments, indicating the presence of random destruction. The cause of this was not established. Since some of the cells counted by the hemolytic technique had been treated with $\mathrm{Cr}^{51}$, the possibility of a toxic effect of chromium must be considered. The proportion of treated cells injected, however, never exceeded 4 per cent of the total; and any effect from this source would therefore be insignificant. Moreover, assuming that the random loss in Expt. 1.1.a (Table II) is due to random destruction as a result of the action of $\mathrm{Cr}^{51}$ on some of the cells, we may calculate that if all the cells had been so treated the rate of destruction would be greater by a factor equal to the increase in the proportion of cells treated. That is since the value of $\mathrm{k}$ in the hemolytic method was 0.0046 with 2.6 per cent of the cells treated with $\mathrm{Cr}^{51}$ the expected value of $k$ with 100 per cent of cells treated would be $0.0046 / .026=0.177$. This is much more than ten times the value actually found, viz., 0.0125 . Damage from chromium is therefore highly improbable. In the greater number of experiments random destruction as measured by the hemolytic method is not significantly greater than zero in spite of the fact that some of the cells had been exposed to chromium, which therefore cannot in these cases have been the cause of any random destruction. The recipients remained in excellent health throughout the experimental period, and no detectable incompatibility between donor and recipient blood was found either before or after the experiment by multiple compatibility tests including the indirect antiglobulin test (Coombs). De- 
velopment of an antibody during the course of the experiment is also very unlikely since the rate of random destruction is, as closely as one can judge, constant throughout. One must conclude that even in the blood of so-called normals there may be present a mechanism of unknown nature causing random loss of red cells. That this has not previously been noted in man is probably to be explained by its being obscured by the experimental errors involved in the Ashby method. It has, however, uniformly been seen in apparently healthy cats and rabbits, and also, although only occasionally, in dogs when blood was tagged with $\mathrm{Fe}^{59}$ (4). In the remainder of the counts made by the hemolytic method $k$ was not significantly greater (or, in one instance, less) than zero, that is to say, there was no random destruction, but only disappearance as a result of senescence.

The increased rate of calculated random loss in the chromium experiments is probably to be attributed to elution. It is measured by the differences in constants of random loss obtained by the chromium and hemolytic methods; values are given in Table II. Standard errors are computed by taking the square root of the sum of the squares of the standard errors of the two k's. Because of the large standard error it was impossible to show significant differences between different recipients. The average daily rate of loss was .0090 . This might result either from a toxic effect of the chromium or from elution, or even as Ebaugh, Emerson, and Ross (12) suggest, unequal effects of chromium on cells of different ages. This last would imply that on any day a red cell would take up 0.9 per cent less chromium than it would have done the day before, an assumption for which there is no other evidence. Nor is there any independent reason for attributing it to a toxic effect of the isotope. It is clearly unrelated to the specific activity of the chromium used, and Ebaugh, Emerson, and Ross were unable to relate it to chromium concentrations. On the other hand the figure 0.9 per cent is very close to the value of 1 per cent which Necheles, Weinstein, and LeRoy (3) found for elution, to which it may therefore be most probably ascribed. This would represent a biological half-life of 77 days which is exactly the same as that computed by Ebaugh, Emerson, and Ross (12).
Finally, analysis of the curve gives a value for the initial reading, $\mathrm{N}_{0}$. It is interesting to compare this with values actually obtained within the first 24 hours, values which do not enter into the determination of this constant. With one exception (2.4.a Table II) values determined by hemolysis are scattered around the line; in all the radiochromium curves and one of the hemolytic curves the initial values lie above the line, often dropping sharply. Ebaugh, Emerson, and Ross (12) found that the chromium curve was 6.7 per cent, on the average, above the curve determined by agglutination during the first 48 hours. Similar observations have been made by Mollison and Veall (18), who found a loss of chromium of about 6 per cent in the first 24 hours. Although this may be due to more rapid elution, these facts might also be explained by assuming that the chromium treatment produces irreversible damage in a few of the cells treated; these disappear for the most part within twenty-four hours after transfusion. In this respect the damage resembles that produced by storage procedures, and in all these cases it may be the result of the manipulations such as centrifuging, transfusing, etc., and not due to the chromium itself. It would not therefore be surprising to find it also in one of the curves obtained by differential hemolysis (2.4.a Table II). That it occurs so frequently means that considerable caution must be used in interpreting this portion of the curve. Apart from this there is no real evidence that chromium has any deleterious effect on the survival of the cells in which it has been incorporated.

\section{SUM MARY}

In order to distinguish between the innate life span of erythrocytes and environmental factors affecting their survival, red cells from the same donor were followed after transfusion into three different healthy recipients in each of two experiments. In every case the number of surviving cells was estimated by two methods : tagging with radiochromium and a new modification of the Ashby method using hemolysis instead of agglutination. Details of this method are given. Curves obtained by both methods were analyzed by a mathematical method not previously used for this work, and it was possible to obtain relatively precise estimates 
of life span and coefficient of random destruction, together with their standard deviations. The life span, $129 \pm 5$ days in one case and $114 \pm 8$ in the other, was found to depend solely on the donor and to be independent of environment and the method. Random loss of radiochromium, presumably from elution, averaged 0.9 per cent daily; differences due to environment were not detectable. Random destruction of significant magnitude $o c-$ curred in two of the six healthy recipients; it was not a toxic effect of the chromium, nor could antibodies capable of causing it be demonstrated. By projecting the curve obtained by this mathematical analysis backwards to zero time it was found that in one of the hemolytic curves and all of the radiochromium ones there was a definite drop in the count over the first twenty-four hours unaccounted for by elution (unless at a much greater rate during this period), random destruction or senescence. It was suggested that it was a result of damage to the blood preparatory to and during transfusion. No toxic effects of radiochromium were found.

\section{ACKNOWLEDGMENTS}

We are deeply indebted to Mr. Malcolm Turner for advice and help in the mathematical treatment of the data.

\section{REFERENCES}

1. Dornhorst, A. C., The interpretation of red cell survival curves. Blood, 1951, 6, 1284.

2. Eadie, G. S., and Brown, I. W., Jr., Red blood cell survival studies. Blood, 1953, 8, 1110.

3. Necheles, T. F., Weinstein, I. M., and LeRoy, G. V., Radioactive sodium chromate for the study of survival of red blood cells. I. The effect of radioactive sodium chromate on red cells. J. Lab. \& Clin. Med., 1953, 42, 358.

4. Brown, I. W., Jr., and Eadie, G. S., An analytical study of in vivo survival of limited populations of animal red blood cells tagged with radioiron. J. Gen. Physiol, 1953, 36, 327.

5. Schiff, F., Die Blutgruppen und ihre Anwendungsgebiete. Berlin, Springer, 1933, p. 17.

6. Lyon, W. S., Disintegration of $\mathrm{Cr}^{\mathrm{at}}$. Physical Rev., 1952, 87, 1126.

7. Hurley, T. H., and Weisman, R., Jr., The determination of the survival of transfused red cells by a method of differential hemolysis. J. Clin. Invest., 1954, 33, 835.

8. Salk, J. E., Bailey, M. L., and Laurent, A. M., A safe immunologic adjuvant for enhancing the height and persistence of antibody response to influenza virus vaccines in man. J. Clin. Invest., 1951, 30, 669.

9. Brown, I. W., Jr., Photographic method for enumeration of Ashby and total red cell counts. J. Lab. \& Clin. Med., 1953, 41, 796.

10. Eadie, G. S., Brown, I. W., Jr., Hardin, H. F., and Curtis, W. G., To be published.

11. Sheets, R. F., Janney, C. D., Hamilton, H. E., and DeGowin, E. L., Studies with inagglutinable erythrocyte counts. III. Kinetics of erythrocyte destruction in human beings. J. Clin. Invest., 1951, 30, 1272.

12. Ebaugh, F. G., Jr., Emerson, C. P., and Ross, J. F., The use of radioactive chromium 51 as an erythrocyte tagging agent for the determination of red cell survival in vivo. J. Clin. Invest., 1953, 32, 1260.

13. DeGowin, E. L., Ellis, J. A., Sheets, R. F., Hamilton, H. E., and Janney, C. D., Studies with inagglutinable erythrocyte counts. IV. Graphic analyses of rates of production and destruction of human erythrocytes. J. Clin. Invest., 1954, 33, 163.

14. Deming, W. E., Statistical Adjustment of Data. New York, John Wiley \& Sons, 1943.

15. Bartlett, M. S., Contingency Table Interactions. Suppl. J. Roy. Stat. Soc., 1935, II, 248.

16. Fisher, R. A., The Design of Experiments. 2nd ed., Edinburgh, Oliver and Boyd, 1937.

17. Cochran, W. G., and Cox, G. M., Experimental Designs, New York, Wiley, 1950.

18. Mollison, P. L., and Veall, N., The use of isotope ${ }^{\circ} \mathrm{Cr}$ as a label for red cells. Brit. J. Haemat., 1955, 1,62 . 